\title{
Stable Expression of Anti-CD52 Monoclonal Antibody Using a Bicistronic Vector System
}

\author{
Azam Rahimpour ${ }^{1,2, *}$, Hadi Bayat ${ }^{1,2}$, Meysam Omidi ${ }^{1,2}$, Morvarid Peyrovan ${ }^{3}$, Omid Mohammadian $^{4}$, Fatemeh Naderi $^{5}$ \\ ${ }^{1}$ Medical Nano-Technology \& Tissue Engineering Research Center, Shahid Beheshti University of Medical Sciences, Tehran, Iran \\ ${ }^{2}$ Department of Tissue Engineering and Regenerative Medicine, School of Advanced Technologies in Medicine, Shahid Beheshti University of Medical Sciences, \\ Tehran, Iran \\ ${ }^{3}$ Deaprtment of Cell and Molecular Biology, Pharmaceutical Sciences Branch, Islamic Azad University, Tehran, Iran \\ ${ }^{4}$ Departments of Clinical Biochemistry, School of Medicine, Shahid Beheshti University of Medical Sciences, Tehran, Iran \\ ${ }^{5}$ Department of Genetics, School of Advanced Sciences, Islamic Azad University, Tehran Medical Branch, Tehran, Iran \\ *Corresponding author: Rahimpour A, School of Advanced Technologies in Medicine, Taleghani Educational Hospital, Araabi St., Yaman Ave, Chamran High Way, Tehran \\ 1985711151, Iran; E-mail: rahimpour.az@gmail.com \\ Received: Aug 14, 2016; Accepted: Aug 27, 2016; Published: Sep 22, 2016 \\ Copyright: (C) 2016 Bayat et al. This is an open-access article distributed under the terms of the Creative Commons Attribution License, which permits unrestricted use \\ distribution, and reproduction in any medium, provided the original author and source are credited.

\begin{abstract}
The efficient development of stable monoclonal antibody-producing mammalian cells is a tedious and time-consuming process due to the structural complexity of these molecules. The ratio of the light-chain to heavy-chain expression is critical for the assembly and successful production of functional antibodies. Different vector-design strategies have been employed for the optimal expression of monoclonal antibodies in mammalian cells. In the current study, a bicistronic expression based on the encephalomyocarditis virus internal ribosomal entry site (ECMV IRES) element was used for the development of Chinese hamster ovary ( $\mathrm{CHO}$ )-stable cell pools expressing an anti-CD52 antibody. The successful expression of the monoclonal antibody in $\mathrm{CHO}$ cells was achieved with the maximum titer of $20 \mu \mathrm{g} / \mathrm{l}$. Our results here show that IRES-mediated bicistronic expression is an efficient method for the stable expression of monoclonal antibodies in $\mathrm{CHO}$ cells.
\end{abstract}

Keywords: Monoclonal antibody; Biscistronic expression; Chinesehamster ovary cells

\section{Introduction}

Monoclonal antibodies (mAbs) have been extensively used for the treatment of a wide range of human diseases. In fact, today, therapeutic monoclonal antibodies are categorized as the fastest growing and bestselling biopharmaceuticals [1]. The main advantages of monoclonal antibodies in comparison to small-molecule drugs are longer half-life, high-affinity binding to target molecules, the possibility of the development of specific mAbs for a wide range of antigens, and the ability to use the host's immune-system effector functions such as antibody-dependent cellmediated cytotoxicity (ADCC) and complement-dependent cytotoxicity (CDC) $[2,3]$.

Whole monoclonal antibodies are primarily produced in mammalian expression systems including CHO, Sp2/0, and NSO cells mainly because these host systems have the ability to perform the necessary posttranslational modifications such as glycosylation and disulphide-bond formation [4]. The successful expression of the mAbs is also dependent on the proper folding and assembly of the light chain and heavy chain. The efficient and controlled coexpression of these two polypeptides is an important consideration in the design of $\mathrm{mAb}$ expression vectors. It has been suggested that the excess ratio of light chain to heavy chain is essential for the formation of a correctly folded antibody molecule [5].

Internal ribosome entry sites (IRESs) are RNA elements that can stimulate internal cap-independent translation of mRNAs. These elements are naturally present in the $5^{\prime}$ untranslated region (UTR) of cellular and viral mRNAs. Their main function is to facilitate the selective expression of desired genes when the main cap-dependent translation system is suppressed due to viral infection or other stress stimuli. When placed between two or three genes, IRESs allow their coexpression from a single transcript. In this situation, the first gene is translated via cap-dependent mechanism, while the rest of the genes are translated through cap-independent translation [6,7].

IRESs have been expensively used for coexpression of multiple genes in mammalian cells. The main applications include the design of gene-therapy vectors, transgenic studies, and heterologous expression of recombinant proteins. It has been shown that the efficiency of capindependent translation is lower than the main cap-dependent system. This property has been well suited to the mAb expression by placing the light-chain and heavy-chain coding regions upstream and downstream of an IRES element, respectively $[8,9]$.

Stem cell transplantation (SCT) has become an efficient therapeutic option for hematologic malignancies, nonmalignant hematologic disorders, and even nonhematologic disorders such as autoimmune diseases. Where autologous SCT is associated with fewer complications, allogeneic SCT offers several advantages including the lower risk of disease relapse due to the presence of residual tumor cells and the ability to exert tumor versus malignancy effect due to the donorimmunocompetent cells in the graft. However, allogeneic transplant is also associated with life-threatening complications such as graftversus-host disease (GvHD). Therefore, different strategies have been developed to block T-cell function including the in vitro removal of the donor $\mathrm{T}$ cells, the use of calcineurin inhibitors, or the in vivo administration of antibodies for lymphocyte depletion [10,11].

Anti-CD52 monoclonal antibodies have shown promising results in reducing the GVHD in SCT, treatment of lymphocyte malignancies, and management of autoimmune disorders such as multiple sclerosis and rheumatoid arthritis. The main mechanism of action of these 
Citation: Rahimpour A, Bayat H, Omidi M, Peyrovan M, Mohammadian O, Naderi F (2016) Stable Expression of Anti-CD52 Monoclonal Antibody Using a Bicistronic Vector System. Biol Med (Aligarh) 8: 341. doi:10.4172/0974-8369.1000341.

Page 2 of 4

agents is triggering lymphocyte cytotoxicity through ADCC, CDC, and apoptosis $[12,13]$.

In the current study, the efficiency of a bicistronic-expression vector system in the stable expression of an anti-CD52 monoclonal antibody in $\mathrm{CHO}$ cells has been examined.

\section{Materials and Methods}

\section{Cell culture}

CHO-K1 cells (ATCC CCL-61) were cultured in DMEM/F12 medium supplemented with $10 \%$ fetal bovine serum (FBS), $100 \mathrm{U} / \mathrm{ml}$ penicillin, $100 \mu \mathrm{g} / \mathrm{ml}$ streptomycin, and $2 \mathrm{mM} \mathrm{L}$-glutamine (Life Technologies, USA) at $37^{\circ} \mathrm{C}$ in a humidified incubator containing $5 \%$ $\mathrm{CO}_{2}$. For the determination of cell concentration and viability, trypanblue exclusion method was used.

\section{Gene cloning}

The antibody light chain (LC), heavy chain (HC), and ECMV IRES element were first amplified, cloned in intermediate vectors, and sequenced. Then, the IRES was cloned upstream of the heavy chain in the EcoRI and NcoI restriction sites. In the next step, the IRES-HC fragment was cloned downstream of the light chain in EcoRI and NotI sites. Finally the LC-IRES-HC fragment was cloned in the multiplecloning site of the pCMV-Puro expression vector using the NheI and NotI restriction sites to obtain pLCIHC-Puro vector.

\section{Transfection and stable cell-line development}

Transfection was performed using Lipofectamin 2000 reagent (Life Technologies, USA) according to the manufacturer' s protocol. For the development of stable cell pools, $\mathrm{CHO}-\mathrm{K} 1$ cells were transfected with the pLCIHC-Puro expression vector in duplicates. After $48 \mathrm{~h}$, transfectants were diluted in 1:10 ratio, and the antibiotic selection was performed in a medium containing $5 \mu \mathrm{g} / \mathrm{ml}$ puromycin (Life Technologies, USA) for 4 weeks. Resulting cells were cultured in antibiotic-free medium for several passages.

\section{Analysis of antibody expression}

Stable cell pools as well as parental cells were seeded in 24 well plates at the density of $0.05 \times 10^{6}$ cells $/ \mathrm{ml}$. The culture's supernatants were collected at $96-\mathrm{h}$ intervals during the 9 days of culture. For the analysis of $\mathrm{mAb}$ concentration, an enzyme-linked immunosorbent assay (ELISA) in 96 well plates (Greiner, USA) was employed. Briefly, each well was first coated with $1 \mu \mathrm{g}$ of goat antihuman IgG as a capture antibody in $4^{\circ} \mathrm{C}$. Following three washes with phosphate-buffered saline (PBS) containing 0.1\% Tween-20 (Sigma, Germany), $200 \mu$ l of blocking buffer (3\% Skimmed milk in PBS) was added to each well and incubated at $37^{\circ} \mathrm{C}$ for $1 \mathrm{~h}$. The plate was then washed three times, and $100 \mu \mathrm{l}$ of the cell-culture medium and the standard antibody were added in duplicates and incubated at $37^{\circ} \mathrm{C}$ for $1 \mathrm{~h}$. After three washes, $100 \mu \mathrm{l}$ of horseradish peroxidase (HRP)-conjugated goat antihuman Kappa chain (Sigma, Germany) in $1: 10,000$ dilution was added and incubated at $37^{\circ} \mathrm{C}$ for another hour. Following three washes, $100 \mu \mathrm{l}$ of tetramethylbenzidine (TMB) substrate (Sigma, Germany) was added and incubated at room temperature for $20 \mathrm{~min}$. The reaction was stopped by $1 \mathrm{M} \mathrm{HCl}$, and the absorbance at $450 \mathrm{~nm}$ was measured using a plate reader.

\section{Results}

\section{Construction of the expression vector}

The bicistronic-expression vector was constructed through several cloning steps. In the final expression vector, pLCIHC-Puro, the LC-IRES-HC fragment has been inserted downstream of the cytomegalovirus (CMV) promoter. The map of the pLCIHC-Puro expression vector is shown in Figure 1.

\section{Stable cell-line generation}

$\mathrm{CHO}-\mathrm{K} 1$ cells were transfected with the monoclonal-antibody bicistronic-expression construct in duplicate, and two stable cell pools were generated in puromycin-containing medium. After 2 weeks of antibiotic selection, untransfected cells died completely, while cell clones appeared in transfected cells. During two more weeks' culture of transfected cells in puromycin-containing medium, the clones were propagated, and cell pools were developed.

\section{Monoclonal antibody-expression analysis}

Stable cell pools as well as parental cells were cultured in 24 well plates. The culture's supernatants were analyzed for monoclonal antibody-expression level in 3-day intervals during the 9 days of culture. As it is indicated in Figure 2, the sample from day six showed the highest expression level with the titer of $20 \mu \mathrm{g} / \mathrm{l}$.

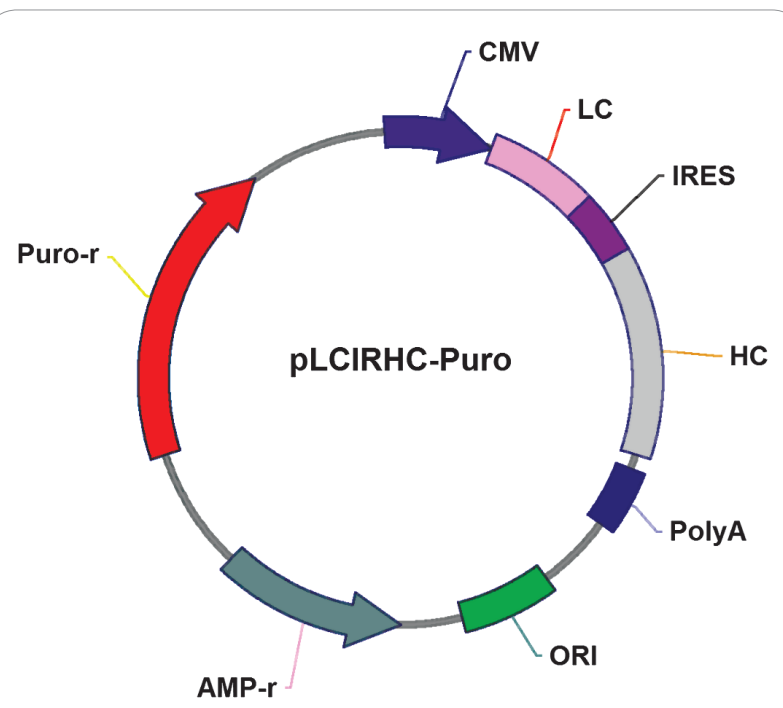

Figure 1: The schematic representation of the bicistronic-expression vector containing light chain (LC), IRES, and heavy chain $(\mathrm{HC})$ is shown

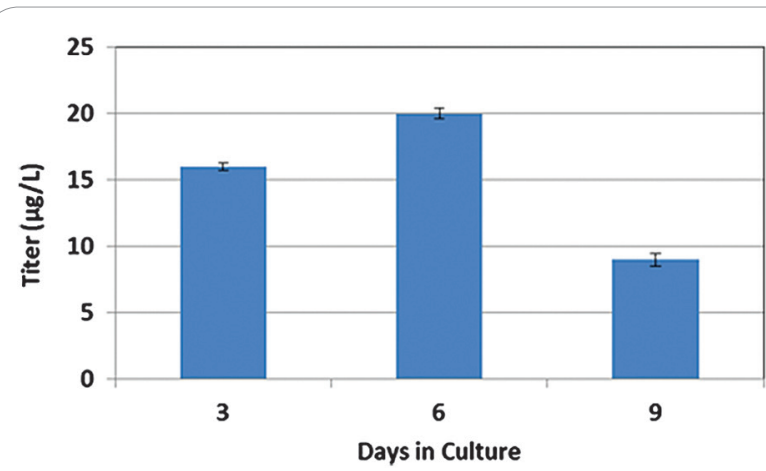

Figure 2: The antibody-expression level during 9 days of culture. The error bars represent the standard deviation of measurements of two independent experiments 
Citation: Rahimpour A, Bayat H, Omidi M, Peyrovan M, Mohammadian O, Naderi F (2016) Stable Expression of Anti-CD52 Monoclonal Antibody Using a Bicistronic Vector System. Biol Med (Aligarh) 8: 341. doi:10.4172/0974-8369.1000341.

Page 3 of 4

\section{Discussion}

Despite tremendous advances in recombinant protein-expression level during the last decades, the development of the stable highproducing cell lines is still a major challenge, especially for more complex proteins such as monoclonal antibodies [14,15]. The complex nature of the antibodies also necessitates the use of mammalian cells as the most potent expression system. In this regard, vectorengineering strategies have proven to be effective for the enhancement of the transgene-expression level as well as its stability in mammalian cells [16].

In fact, the choice of expression vector and its elements can have a profound effect on monoclonal-antibody expression as well as its quality. Therefore, researchers have focused on the evaluation of the different vector-design strategies for the transient and stable expression of monoclonal antibodies. It has been revealed that the LC:HC ratio can affect antibody assembly in the endoplasmic reticulum (ER). Schlatter et al. [17] have shown that antibody production was higher in clones with LC:HC ratios higher than 2:1.

Although the use of two separate vectors for the expression of heavy chain and light chain has been reported, this approach has serious shortcomings such as the possibility of the integration of the two vectors in different genomic sites and the variation of the copy number for each gene which can in turn cause an improper ratio of the expressed light chain to heavy chain, and reduce the possibility of achieving cell clones with high expression level of active antibody.

To deal with these limitations, the use of single-expression vectors containing both light- and heavy-chain coding sequences has been considered. Although the expression of each polypeptide under the control of a separate promoter can solve the problem of integration in a different genomic site, the promoter function can be affected by the transcriptional interference effect [18]. As a result, multicistronic expression systems, which allow the transcription of two or three genes in a single transcript, and the single open reading frame (ORF)expression system, which is based on the translation of both chains as a single polypeptide and their subsequent cleavage, have been employed for monoclonal-antibody expression [19].

In a study by Ho et al. [20], the antibody productivity and the product quality of the cell pools with different LC:HC ratios using the IRES-based tricistronic vectors containing $\mathrm{LC}, \mathrm{HC}$, and the dihydrofolate reductase (DHFR) genes were examined. Product aggregation was more common when the LC:HC ratio was lower while more than $97 \%$ of the product were monomers in cells with the ratio more than 1 . Higher $\mathrm{mAb}$ titers were achieved in pools with the ratio of 3.43. Li et al. [5] have compared the efficiency of antibody expression in dual-promoter and bicistronic expressions. In this study, the bicistronicexpression constructs with the LC-IRES-HC arrangement showed the highest expression level in $\mathrm{CHO}$ cells.

In another report, Ho et al. [19] compared the efficacy of IRES-mediated multicistronic expression and $2 \mathrm{~A}$ peptide-mediated single-ORF expression strategies in antibody-expression level and its quality in $\mathrm{CHO}$ cells. Although the single ORF design with the LC-2A-HC arrangement showed higher expression level compared to LC-IRES-HC design as measured with ELISA, the stable expression using LC-IRES-HC had the lowest level of aggregate formation and the highest monomeric antibodies, proving the higher efficiency of this method.
In the current study, we have used bicistronic expression based on the IRES element with the LC-IRES-HC arrangement. Our expression analysis using ELISA showed up to $20 \mu \mathrm{g} / \mathrm{l}$ titer in the cell-culture supernatant of the stable cell pools. This titer seems rational, considering that transfectants were only selected using antibiotic selection without performing gene amplification. Further studies on analysis of antibody quality in stable cell pools as well as single cell clones are needed to examine the actual efficiency of this expression platform.

\section{Acknowledgments}

The authors declare no financial or commercial conflict of interest. This paper was supported by a grant from the Medical Nano-Technology \& Tissue Engineering Research Center, Shahid Beheshti University of Medical Sciences, Tehran, Iran.

\section{References}

1. Ecker DM, Jones SD, Levine HL (2014) The therapeutic monoclonal antibody market. MAbs 7(1): 9-14

2. Liu JK (2014) The history of monoclonal antibody development - progress, remaining challenges and future innovations. Ann Med Surg (Lond) 3(4): 113-116.

3. Foltz IN, Karow M, Wasserman SM (2013) Evolution and emergence of therapeutic monoclonal antibodies: what cardiologists need to know. Circulation 127(22): 2222-2230

4. Kunert R, Reinhart D (2016) Advances in recombinant antibody manufacturing Appl Microbiol Biotechnol 100(8): 3451-3461.

5. Li J, Menzel C, Meier D, Zhang C, Dubel S, et al. (2007) A comparative study of different vector designs for the mammalian expression of recombinant $\mathrm{lgG}$ antibodies. J Immunol Methods 318(1-2): 113-124.

6. Filbin ME, Kieft JS (2009) Toward a structural understanding of IRES RNA function. Curr Opin Struct Biol 19(3): 267-276.

7. Khawaja A, Vopalensky V, Pospisek M (2014) Understanding the potential of hepatitis $\mathrm{C}$ virus internal ribosome entry site domains to modulate translation initiation via their structure and function. Wiley Interdiscip Rev RNA 6(2) 211-224.

8. Renaud-Gabardos E, Hantelys F, Morfoisse F Chaufour X, Garmy-Susini B, et al. (2015) Internal ribosome entry site-based vectors for combined gene therapy. World J Exp Med 5(1): 11-20.

9. Makrides SC (1999) Components of vectors for gene transfer and expression in mammalian cells. Protein Expr Purif 17(2): 183-202.

10. Gandhi S, Kulasekararaj AG, Mufti GJ, Marsh JC (2013) Allogeneic stem cell transplantation using alemtuzumab-containing regimens in severe aplastic anemia. Int J Hematol 97(5): 573-580.

11. Gribben JG, Hallek M (2009) Rediscovering alemtuzumab: current and emerging therapeutic roles. $\mathrm{Br} J$ Haematol 144(6): 818-831.

12. Hale G (2001) The CD52 antigen and development of the CAMPATH antibodies. Cytotherapy 3(3): 137-143

13. Holgate RG, Weldon R, Jones TD, Baker MP (2015) Characterisation of a novel anti-CD52 antibody with improved efficacy and reduced immunogenicity. PLoS One 10(9): e0138123.

14. Le H, Vishwanathan N, Jacob NM, Gadgil M, Hu WS (2015) Cell line development for biomanufacturing processes: recent advances and an outlook. Biotechnol Lett 37(8): 1553-1564.

15. Rahimpour A Ahani $R$, Najaei A, Adeli A, Barkhordari F, et al. (2016) Development of genetically modified Chinese hamster ovary host cells for the enhancement of recombinant tissue plasminogen activator expression. Malays J Med Sci 23(2): 6-13.

16. Rahimpour A, Vaziri B, Moazzami R, Nematollahi L, Barkhordari F, et al. (2013) Engineering the cellular protein secretory pathway for enhancement of recombinant tissue plasminogen activator expression in Chinese hamster ovary cells: effects of CERT and XBP1s genes. J Microbiol Biotechnol 23(8): 1116-1122. 
Citation: Rahimpour A, Bayat H, Omidi M, Peyrovan M, Mohammadian O, Naderi F (2016) Stable Expression of Anti-CD52 Monoclonal Antibody Using a Bicistronic Vector System. Biol Med (Aligarh) 8: 341. doi:10.4172/0974-8369.1000341.

Page 4 of 4

17. Schlatter S, Stansfield SH, Dinnis DM, Racher AJ, Birch JR, et al. (2005) On the optimal ratio of heavy to light chain genes for efficient recombinant antibody production by $\mathrm{CHO}$ cells. Biotechnol Prog 21(1): 122-133.

18. Palmer AC, Egan JB, Shearwin KE (2011) Transcriptional interference by RNA polymerase pausing and dislodgement of transcription factors. Transcription 2(1): $9-14$
19. Ho SC, Bardor M, Li B, Lee JJ, Song Z, et al. (2013) Comparison of internal ribosome entry site (IRES) and Furin-2A (F2A) for monoclonal antibody expression level and quality in $\mathrm{CHO}$ cells. PLoS One 8(5): e63247.

20. Ho SC, Bardor M, Feng H, Mariati, Tong YW, et al. (2012) IRES-mediated Tricistronic vectors for enhancing generation of high monoclonal antibody expressing $\mathrm{CHO}$ cell lines. J Biotechnol 157(1): 130-139. 